\title{
Evolution of Solid Phase Homochirality for a Proteinogenic Amino Acid
}

\author{
Cristobal Viedma, ${ }^{,+}$José E. Ortiz, ${ }^{\ddagger}$ Trinidad de Torres, ${ }^{\ddagger}$ Toshiko Izumi, ${ }^{\S}$ and \\ Donna G. Blackmond*,§,II \\ Departamento Cristalografia-Mineralogia, Facultad Geologia, Universidad Complutense, 28040, Madrid, Spain, \\ Laboratorio de Estratigrafía Biomolecular, Escuela Técnica Superior de Ingenieros de Minas de Madrid, Madrid, Spain, \\ and Department of Chemical Engineering and Department of Chemistry, Imperial College, London SW7 2AZ, U.K.
}

The single-handedness of biological molecules has fascinated scientists since Pasteur first separated mirror-image crystals of a tartrate salt. ${ }^{1}$ Several models have been proposed to address the question of how enantiomerically pure solutions or crystalline phases could have emerged from a presumably racemic prebiotic world. $^{2-12}$ Viedma demonstrated the inexorable and random emergence of solid phase single chirality for the inorganic compound $\mathrm{NaClO}_{3}$ initially present as a racemic mixture of two enantiomorphic solid phases in equilibrium with the achiral aqueous phase. ${ }^{9 \mathrm{a}}$ Recently this same phenomenon was demonstrated by some of us ${ }^{10}$ for an intrinsically chiral model amino acid derivative that undergoes facile base-catalyzed solution racemization. This work has stimulated a fertile and ongoing discussion about the mechanism of the process, including extensions to the original model of attrition-enhanced Ostwald ripening, ${ }^{9,12,13}$ as well as the concept that small clusters of molecules may play a role. ${ }^{14,15}$

Experimental proof of concept for the evolution of single chirality in the solid phase to date is limited to model compounds, and therefore experimental demonstration for proteinogenic amino acids or other biological molecules remains an important goal. We report here the first example of the evolution of total enantioenrichment of the solid phase for an essential amino acid mediated by solutionphase racemization. In addition, we explore further the intriguing mechanism for this transformation, showing that the process is inexorable even in the absence of the attrition enhancement reported in our previous work.

The potential for evolution to a single solid-phase chiral state exists for enantiomers that form separate D and L crystals and can undergo solution racemization. We chose to probe this possibility for the proteinogenic amino acid aspartic acid in a nearly racemic $(<10 \%$ ee) mixture of crystals in equilibrium with its solution phase under racemizing conditions (Scheme 1).

Of the 20 amino acids that are directly encoded for protein synthesis by the standard genetic code, aspartic acid is one of only two that crystallize separately as D and L solids under ambient conditions. ${ }^{16,17}$ One of the most abundant amino acids formed in experiments simulating the chemistry of the primitive Earth, ${ }^{18}$ aspartic acid is present in the Murchison meteorite. ${ }^{19}$ Aspartic acid is one of the amino acids forming the sequence calculated for the original ancestral molecule ferrodoxin, ${ }^{20}$ believed to be one of the first proteins formed on earth. ${ }^{21}$

While amino acids are subject to slow racemization over long periods of time (giving rise to the "calamity of racemization", over a geological time frame), most are quite stable on a laboratory time

\footnotetext{
${ }^{\dagger}$ Universidad Complutense.

* Escuela Técnica Superior de Ingenieros de Minas de Madrid.

$\$$ Department of Chemical Engineering, Imperial College.

"Department of Chemistry, Imperial College.
}

Scheme 1. Aspartic Acid Solid Crystals in Equilibrium with Solid Solution Enantiomers under Racemizing Conditions

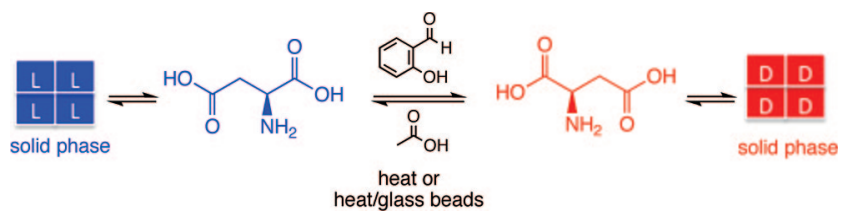

scale. Yoshioka recently developed an efficient procedure for racemization of amino acids by reaction with aldehydes in acidic media. $^{22}$

Figure 1 monitors solid-phase ee over time for experiments stirring saturated solution-solid mixtures of nonenantiopure aspartic acid in acetic acid with catalytic salicylaldehyde at elevated temperature in both the presence and absence of $2.5 \mathrm{~mm}$ glass beads (see Supporting Information for details). The data reveal the evolution of solid-phase homochirality under all conditions. With enhanced attrition due to grinding, the characteristic sigmoidal shape of an autoinductive process is observed (left plot). The length of the induction period is sensitive to temperature. Heating aspartic acid suspensions on a hot stirring plate provides a strong temperature gradient with a maximum near $160^{\circ} \mathrm{C}$ that results in a much more rapid amplification of solid-phase single chirality than is found under controlled isothermal conditions at $90{ }^{\circ} \mathrm{C}$. Similarities in the slope of the sigmoidal part of the curves on the left plot for experiments at different temperatures imply that once the system has "taken off" under enhanced attrition conditions, the rate of evolution of solid phase ee is not strongly sensitive to temperature.

Since racemization of amino acids is a more activated rate process than the dissolution/crystallization mass transfer processes, we reasoned that the thermal energy imparted to the system to promote the former chemical process might be sufficient to promote
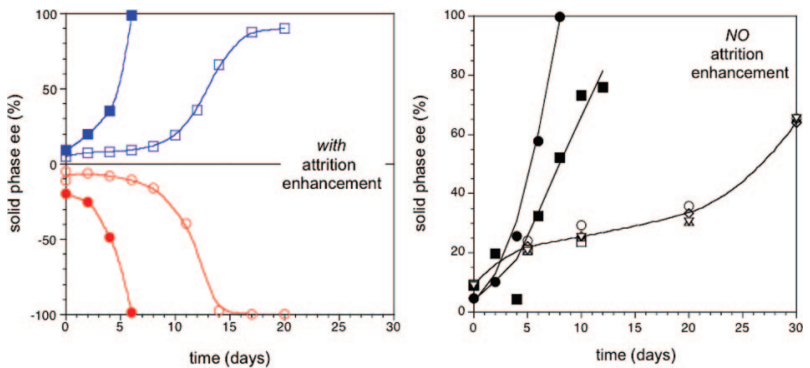

Figure 1. Evolution of solid-phase ee for D and L aspartic acid under racemizing conditions. Left: attrition-enhanced conditions. Filled symbols: gradient heating to $160{ }^{\circ} \mathrm{C}$. Open symbols: isothermal at $90{ }^{\circ} \mathrm{C}$. Positive ee values are assigned to the naturally occurring L-asp. Right: stirring in the absence of glass beads. Filled circles: gradient heating to $160^{\circ} \mathrm{C}$. Filled squares: under reflux at $125^{\circ} \mathrm{C}$. Open symbols: isothermal heating to $105^{\circ} \mathrm{C}$. 
Scheme 2. Evolution of Solid-Phase Homochirality in the Presence and Absence of Mechanical Energy Input ${ }^{a}$

with enhanced attrition

without enhanced attrition
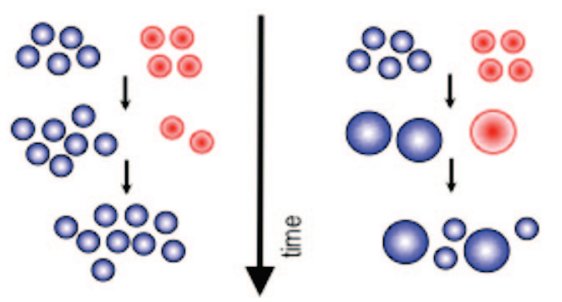

${ }^{a}$ Uniform crystal size, and therefore surface area, is maintained under enhanced attrition conditions due to mechanical grinding. Without attrition enhancement, overall surface area decreases due to crystal growth. Solution racemization of enantiomers drives the evolution to a single chiral solid state in both cases.

the latter physical processes, even without mechanical energy input from grinding. Experiments carried out under similar conditions without addition of glass beads shown in Figure 1 (right) confirm that the trend toward a single chiral state is also observed under these nonattrition-enhanced conditions.

Solid phase enantioenrichment evolves faster in the presence of glass beads than in their absence at given temperature conditions (99\% ee compared to $58 \%$ ee after 6 days). In the absence of enhanced attrition, the conversion to a single chiral solid state is strongly influenced by temperature; the rate of solid-phase enrichment is tripled under reflux at $125^{\circ} \mathrm{C}$, compared to heating at 105 ${ }^{\circ} \mathrm{C}$, both in the absence of attrition by glass beads. Even more strikingly, the form of the conversion profile obtained in the absence of enhanced attrition is altered significantly by temperature. At lower temperature, a steady, gradual conversion is observed rather than the typical autoinductive profile.

The dynamic processes of crystal dissolution and growth are key to understanding these results. Energy input promotes the preferential dissolution of smaller crystals as expected according to the Gibbs-Thomson rule. This also provides a driving force for preferential growth of larger crystals, as dictated by Ostwald ripening. Since the system is close to equilibrium, dissolution and recrystallization remain nearly balanced. Modeling of these processes reported in ref 12a has quantified the effects of a number of variables, including the exponential profile for the evolution of ee, as observed in Figure 1 (left). Enhanced attrition keeps the average particle size and the total surface area of L and D crystals roughly constant; the net change in L (or D) surface area over time is proportional to the difference between the available $\mathrm{L}$ and $\mathrm{D}$ surface areas at any given time, resulting in an exponential decay of one and increase of the other.

When the process is carried out at $105^{\circ} \mathrm{C}$ in the absence of glass beads, however, evolution of ee over time is not exponential. One possible explanation is that, in the absence of enhanced attrition, the Ostwald ripening process is not countered as effectively as it is by the continual disintegration of crystals caused by grinding. Particles are able to grow larger before ultimately breaking up due to collisions with each other, the vessel walls, or the stirring bar. The evolution toward solid phase homochirality persists, but the predicted exponential solid-phase enantioenrichment is tempered by a less than exponential increase in the crystal surface area for the dominant enantiomer. A comparison of the process in the presence and absence of attrition enhancement is illustrated in Scheme 2.

These results show that the emergence of a state of solid-phase single chirality for a proteinogenic amino acid may be achieved in a near equilibrium process even in the absence of mechanical energy input leading to enhanced attrition of crystals. While these exponential and nearly linear ee profiles cannot of themselves rule out the role of clusters in the mechanism for the evolution of solid phase single chirality, a simple model for our results is suggested on the basis of molecular processes of dissolution/recrystallization coupled with solution racemization. Studies to quantify these observations further are ongoing.

Acknowledgment. D.G.B. gratefully acknowledges unrestricted research funds from AstraZeneca. D.G.B. holds a Royal Society Wolfson Research Merit Award. C.V. is grateful to the NORDITA Center for a useful exchange of ideas.

Supporting Information Available: Details of experimental and analytical procedures. This material is available free of charge via the Internet at http://pubs.acs.org.

\section{References}

(1) Pasteur, L. C. R. Hebd. Séanc. Acad. Sci. Paris 1848, 26, 535.

(2) Havinga, E. Biochem. Biophys. Acta 1954, 13, 171-174.

(3) Frank, F. C. Biochim. Biophys. Acta 1953, 11, 459-463.

(4) Calvin, M. Molecular Evolution; Oxford University Press: Oxford, 1969.

(5) Bonner, W. A. Orig. Life Evol. Biosphere 1991, 21, 59-111.

(6) (a) Soai, K.; Shibata, T.; Morioka, H.; Choji, K. Nature 1995, 378, 767768. (b) Blackmond, D. G.; McMillan, C. R.; Ramdeehul, S.; Schorm, A.; Brown, J. M. J. Am. Chem. Soc. 2001, 123, 10103-04. (d) Blackmond, D. G. Proc. Natl. Acad. Sci. U.S.A. 2004, 101, 5732-36.

(7) Kondepudi, D. K.; Kaufman, R. J.; Singh, N. Science 1990, 250, 975-77.

(8) Weissbuch, I.; Leiserowitz, L.; Lahav, M. Top. Curr. Chem. 2005, 253, 123-165.

(9) (a) Viedma, C. Phys. Rev. Lett. 2005, 94, 065504. (1-4). Viedma, C. Astrobiol. 2007, 7, 312-319.

(10) (a) Klussmann, M.; Iwamura, H.; Mathew, S. P.; Wells, D. H., Jr.; Pandya, U.; Armstrong, A.; Blackmond, D. G. Nature 2006, 441, 621-623. (b) Klussmann, M.; White, A. J. P.; Armstrong, A.; Blackmond, D. G. Angew. Chem., Int. Ed. 2006, 45, 7985-7989. (c) Klussmann, M.; Blackmond, D. G. Chem. Commun. 2007, n/a, 3990-3996.

(11) Noorduin, W. L.; Izumi, T.; Millemaggi, A.; Leeman, M.; Meekes, H.; Van Enckevort, W. J. P.; Kellogg, R. M.; Kaptein, B.; Vlieg, E.; Blackmond, D. G. J. Am. Chem. Soc. 2008, 130, 1158-1159.

(12) (a) Noorduin, W. L.; Meekes, H.; Bode, A. A. C.; van Enckevort, W. J. P.; Kaptein, B.; Kellogg, R. M.; Vlieg, E. Cryst. Growth Des. 2008, 8, 16751681. (b) Noorduin, W. L.; Meekes, H.; Van Enckevort, W. J. P.; Millemaggi, A.; Leeman, M.; Kaptein, B.; Kellogg, R. M.; Vlieg, E. Angew. Chem., Int. Ed. 2008, 47, 6445-6447. (c) Kaptein, B.; Noorduin, W. L.; Meekes, H.; van Enckevort, W. J. P.; Kellogg, R. M.; Vlieg, E. Angew. Chem., Int. Ed. 2008, 47, 7226-7229.

(13) (a) Blackmond, D. G. Chem.-Eur. J. 2007, 13, 3290-3295. (b) Blackmond, D. G. Chem.-Eur. J. 2007, 13, 10306-10311.

(14) (a) Crusats, J.; Veintemillas-Verdaguer, S.; Ribó, J. M. Chem.-Eur. J. 2006, 12, 7776-7781. (b) Crusats, J.; Veintemillas-Verdaguer, S.; Ribó, J. M. Chem.-Eur. J. 2007, 13, 10303-10306.

(15) McBride, J. M.; Tully, J. C. Nature 2008, 452, 161-162.

(16) For detailed information on phase behavior, see: Jacques, J.; Collet, A.; Wilen, S. H. Enantiomers, Racemates and Resolution; Krieger: FL, 1994.

(17) Only ca. $15 \%$ of all known chiral compounds crystallize as separate D and L compounds (conglomerates), with the majority showing a thermodynamic preference for heterochiral $\mathrm{L}-\mathrm{D}$ interactions (forming what are known as racemic compounds). The disalt of tartaric acid separated by Pasteur's tweezers is an example of a conglomerate, while neutral tartaric acid forms a racemic compound.

(18) Fox, S. W. Geochim. Cosmochim. Acta 1995, 59, 1213-1214.

(19) Cronin, J. R.; Pizarello, S.; Cruikshank, D. P. In Meteorites and the Early Solar System; Kerridge, J. F.; Matthews, M. S., Eds.; University Arizona Press: Tucson, 1988; pp 819-857.

(20) Eck, R. V. Science 1966, 152, 363-366.

(21) Hall, D. O.; Rao, K. K. Nature 1971, 233, 136-138.

(22) Yoshihoka, R. Top. Curr. Chem. 2007, 269, 83-132. 